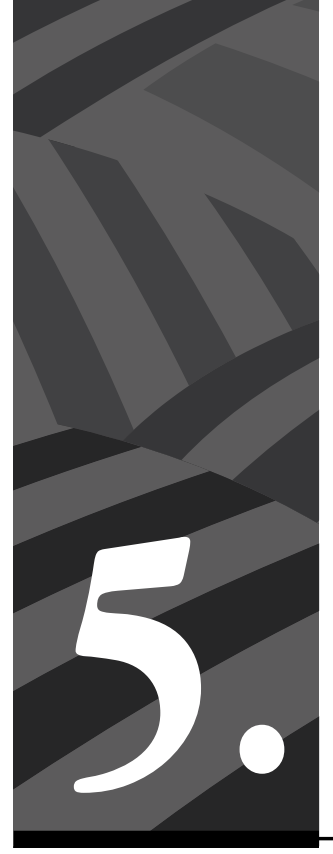

El tejido y la sororidad y su aporte a la construcción de memoria. El caso de las Tejedoras por la Memoria de Sonsón 


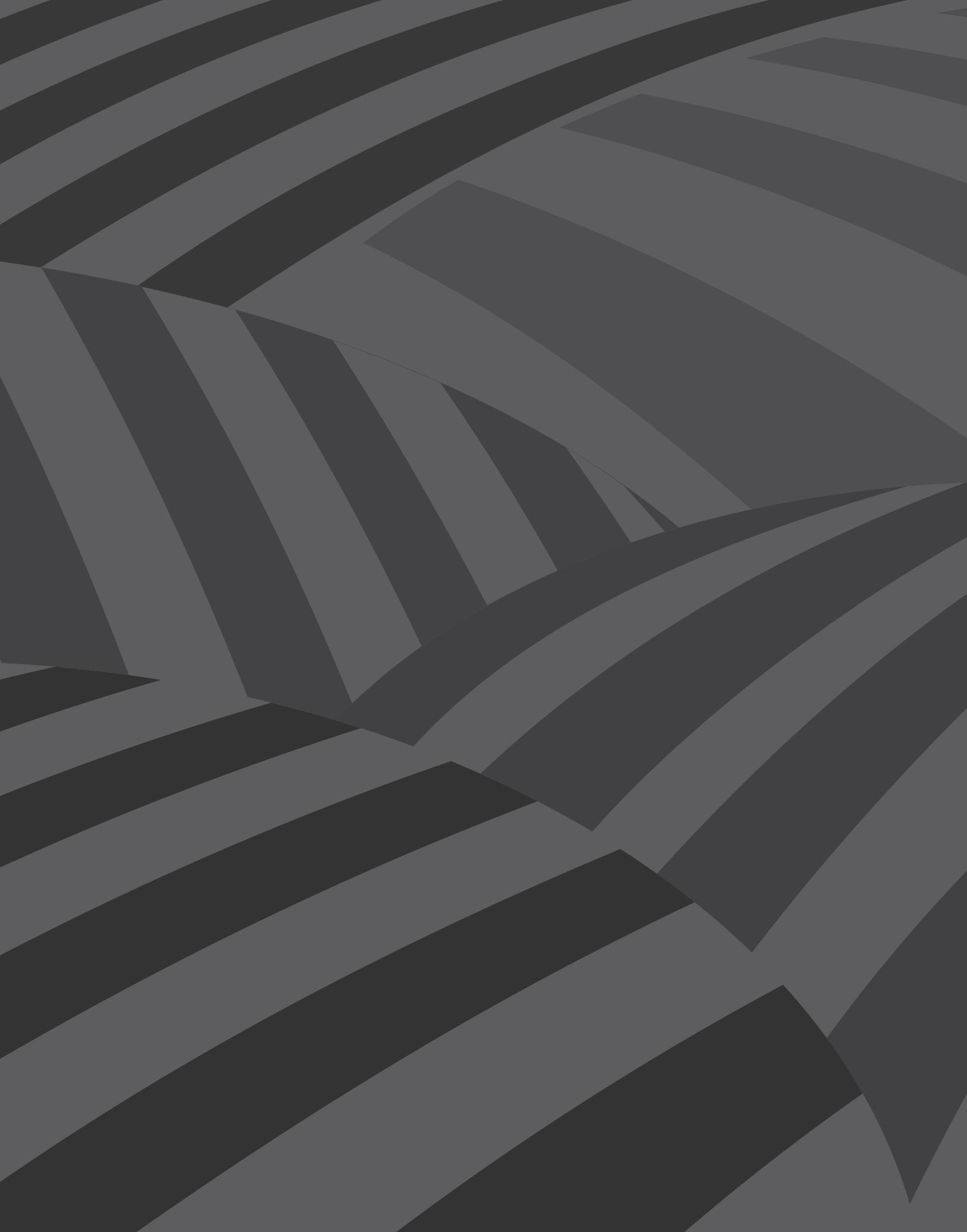




\section{El tejido y la sororidad y su aporte a la construcción de memoria. El caso de las Tejedoras por la Memoria de Sonsón*}

Por Ana María Sossa Londoño**; Marcela María Vergara Arias ${ }^{* * *}$

Resumen: El presente artículo expone los resultados de una investigación adelantada con mujeres organizadas en torno a la construcción de memoria como forma de superación del conflicto armado en Colombia. Dichas experiencias muestran cómo, desde la cotidianidad, es posible generar procesos de construcción de tejido social, sororidad y empoderamiento que posibiliten la recuperación misma de la memoria, el aporte a la paz y otra forma de construir sociedad como alternativa a la violencia armada que por muchos años afectó la vida de las mujeres en nuestro país. Así mismo, el artículo da cuenta de las vivencias de las mujeres en el municipio de Sonsón (Antioquia) que, organizadas y movilizadas a través del Costurero Tejedoras por la Memoria de Sonsón, han hecho de este espacio un referente para la construcción de la paz y el empoderamiento, en un proceso de reconciliación social.

Palabras clave: sororidad, memoria, tejido, redes comunales, mujeres.

\section{Knitting and Sorority, and its Contribution to the Construction of Memory. The Case of the Weavers of Memory from Sonsón}

Abstract: This article shows the results of an investigation carried out with women organized around the construction of memory as a way to overcome the armed conflict in Colombia. These experiences show how, from the daily life of women, is possible to generate processes of social fabric construction, sorority and empowerment that makes possible the recovery of memory, the contribution to peace and another way of building society, as an alternative to

* Artículo basado en el trabajo de grado de Ana María Sossa Londoño, orientado por Marcela Vergara Arias, en la Maestría en Desarrollo de la Universidad Pontificia Bolivariana (UPB), Medellín

** Diseñadora de vestuario y magíster en Desarrollo de la UPB. Docente investigadora de la Facultad de Diseño de Vestuario de la UPB en Medellín. Correo electrónico: anamaria.sossa@upb.edu.co

*** Ph. D. en Sociología. Profesora Asociada de la UPB, campus Medellín. Correo electrónico: marcela.vergara@upb.edu.co 
the armed violence that for many years affected the lives of women in our country. It gives an account of the experiences of women in the municipality of Sonsón (Antioquia) that, organized and mobilized through the Costurero Tejedoras por la Memoria of Sonsón, have made of the Costurero, a reference for the construction of peace and empowerment leading to processes of social reconciliation. This research is within the framework of the degree work carried out by Ana María Sossa Londoño and directed by Marcela Vergara Arias in the Master's Degree in Development at the Universidad Pontificia Bolivariana in Medellín.

Keywords: sorority, memory, knitting, community networks, women.

Cómo citar este artículo: Sossa Londoño, Ana María y Vergara Arias, Marcela María (2019). El tejido y la sororidad y su aporte a la construcción de memoria. El caso de las Tejedoras por la Memoria de Sonsón. Revista Controversia, 213, 191-226.

Fecha de recepción: 14 de marzo de 2019

Fecha de aprobación: 18 de junio de 2019

Como en verdad vivimos siempre, en una rutina de gestos $y$ voces y trayectos, con todo el pasado bajo la piel y a flor de lenguaje, para ser despertado por momentos, súbitamente, quizá por otra voz, por una circunstancia, por un encuentro. Y luego el decir vuelve a cerrarse, para permanecer, pero diferente. Arfuch, 2013, p. 15.

\section{Introducción}

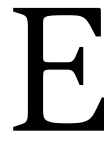
ste trabajo busca rescatar la importancia de los temas de recuperación de la memoria en el contexto actual e histórico —el posacuerdo del conflicto-, que actualmente vive Colombia. El trabajo en torno a las dimensiones del conflicto y sus consecuencias en el plano de la vida colectiva de una sociedad es una forma de aportar a la transformación de las relaciones conflictivas, desde el reconocimiento de prácticas sociales solidarias y no-violentas. La experiencia de las Tejedoras por la Memoria del municipio de Sonsón Antioquia demuestra que, desde las relaciones de las mujeres y la sororidad, es posible 
generar procesos que transformen el conflicto, en este caso, a través del tejido y el arte textil como elementos que posibilitan la visibilización de acciones performativas de construcción del conocimiento y la memoria colectiva. Estas acciones permiten reivindicar a las comunidades vulneradas afectadas en sus derechos humanos por la violencia sistemática del país y brindar posibilidades de no repetición. La recuperación de la memoria, y todo lo que se reivindica a partir de las prácticas colectivas de las mujeres, sirven de base para narrar otras formas de convivencia, de pensar el conflicto y de construir memoria desde la acción, la recordación y el no olvido para la justicia.

El Costurero Tejedoras por la Memoria de Sonsón representa un espacio de resiliencia para las mujeres que han sufrido los efectos devastadores del conflicto armado colombiano, constituido por las mujeres que lo conforman como una red de apoyo, solidaridad, escucha y sanación. Para ellas, la pertenencia a este espacio les ofrece la oportunidad de disipar las tristezas y establecer vínculos con otras mujeres a partir del encuentro y la socialización de su vida cotidiana y de las oportunidades que de allí se desprenden. El tejido hila las historias de las mujeres y la memoria colectiva; en esa medida, el costurero evidencia el poder creativo, mediante la práctica del tejido. Lo anterior faculta la capacidad de agencia en las esferas micropolíticas y en la posibilidad de afirmarse como mujeres y como organizaciones de las mismas. El tejido refleja, entonces, la necesidad de entrelazar fortalezas comunes de las mujeres; así, configura acciones comunes horizontales, críticas y participativas.

Se sabe que el conflicto armado en Colombia produjo miles de víctimas durante los más de 60 años de existencia. Si bien las vidas cobradas han sido mayoritariamente de los hombres - participantes directos en las confrontaciones de la guerra-, un alto porcentaje de las víctimas está representado por las mujeres, que han debido sobrellevar la pérdida de sus familias, hijos, hermanos, vecinos, la destrucción de sus espacios de encuentro y territorios, el desarrollo de su vida cotidiana y el desconcierto frente a sus proyectos de vida. 
Las mujeres del municipio de Sonsón en Antioquia ${ }^{1}$, y en general todos sus habitantes, vivenciaron los acontecimientos y los procesos violentos que el conflicto armado trajo consigo. Según Grisales (2016), entre finales de la década de los noventa y principios de la década del 2000, algunos de los hechos victimizantes sufridos en esta región fueron: la intimidación basada en el terror, la extorsión, el secuestro, el desplazamiento forzado, los asesinatos selectivos, los homicidios indiscriminados, los retenes ilegales, las amenazas, las desapariciones forzadas y las minas antipersonales. En este municipio tenían presencia el Frente 9 y el Frente 47 de las Fuerzas Armadas Revolucionarias de Colombia-Ejército del Pueblo (FARC-EP), el Bloque Carlos Alirio Buitrago del Ejército de Liberación Nacional (ELN), el Bloque José Luis Zuluaga de las Autodefensas Campesinas del Magdalena Medio y las Fuerzas Militares del Ejército Nacional, todos ellos en disputa por este territorio.

A mediados del año 2002, en el Centro Recreacional La Pinera, ubicado en la vereda Río Arriba, zona rural del municipio de Sonsón, a 3 km del casco urbano, se presentó un enfrentamiento entre las Fuerzas Militares del Ejército Nacional de las tropas del Batallón Juan del Corral y las Autodefensas Campesinas del Magdalena Medio (ACMM). En este evento, cayeron, por parte del Ejército, 18 jóvenes sonsoneños que se encontraban en entrenamiento militar para ingresar a las filas de las Autodefensas. Aunado a lo anterior, el espacio donde está ubicada La Pinera tenía una connotación negativa para el municipio, razón por la cual, en el año 2005, el municipio de Sonsón y la Universidad de Antioquia deciden transformarla en un claustro académico, en el que hoy está la sede de Sonsón de la Universidad de Antioquia, cuyo objetivo es reemplazar la carga simbólica de este territorio como una zona de combate.

1 El municipio de Sonsón está ubicado en la zona de páramo de la subregión del Oriente antioqueño. Está conformado por ocho corregimientos, 101 veredas y 16 barrios, donde viven 35405 habitantes (DANE, 2005). 
Estos fueron algunos de los hechos violentos a partir de los cuales es posible evidenciar el surgimiento de iniciativas de memoria, organizaciones de víctimas y movimientos sociales, para la reclamación de derechos, la visibilización de las víctimas y las garantías de no repetición. Asimismo, la subregión del Oriente antioqueño «se reconoce como una región donde las organizaciones de víctimas, lideradas principalmente por mujeres se han convertido en testigos y guardianas de las memorias de la guerra» (Jaramillo, 2014, p. 232).

Una de estas iniciativas de memoria es el Costurero Tejedoras por la Memoria de Sonsón, que se formaliza en el año 2009 con el apoyo del Banco Universitario de Programas y Proyectos de Extensión (BUPPE) de la Universidad de Antioquia. Previo a su consolidación, en el año 2004, algunas de sus fundadoras e integrantes más activas se capacitaron como promotoras de vida y salud mental, a través de la metodología de Grupos de Apoyo Mutuo (GAM), en un proyecto adelantado por el Programa por la Paz del Cinep, Conciudadanía y la Asociación Regional de Mujeres del Oriente Antioqueño (AMOR). En el año 2007, se conforma la Asociación de Víctimas por la Paz y la Esperanza del Municipio de Sonsón y en el año 2014 reciben el galardón «Antioqueñas de Oro» por parte de la Gobernación de Antioquia. Este grupo se consolida para «fomentar espacios de participación y formación, intercambiar aprendizajes que resignifiquen la situación de ser víctimas y contribuir a través del tejido a la reconstrucción de la memoria histórica» (Centro Nacional de Memoria Histórica, 2017).

El Costurero está conformado únicamente por mujeres, sobrevivientes de diferentes hechos victimizantes del conflicto armado, pertenecientes a la Asociación Municipal de Víctimas por la Paz y la Esperanza del municipio de Sonsón. Ellas se reúnen semanalmente para construir memoria histórica del municipio y usan los tejidos como narrativa, de modo que estos puedan ser la voz de las víctimas y expresen las situaciones del conflicto, las vivencias, los sentimientos y los saberes, con lo cual la memoria se da a entender como acción. 
En ese contexto se desarrolla esta investigación, desde la experiencia de las tejedoras por la memoria de Sonsón, a partir de lo cual se intenta responder a la pregunta: ¿Cómo el tejido y la sororidad aportan a la construcción de memoria a través del Costurero Tejedoras por la Memoria de Sonsón, durante los años 2015 y 2018? En este sentido, el propósito central fue comprender los aportes del tejido y la sororidad a la construcción de memoria, mediante el Costurero Tejedoras por la Memoria de Sonsón durante los años 2015 y $2018^{2}$.

La metodología utilizada para el desarrollo de la investigación fue de corte cualitativo y buscaba reivindicar las voces de quienes participan en la construcción de procesos de memoria y utilizan el tejido como narrativa para comunicar la memoria. Se concibe la investigación cualitativa como el paradigma que estudia la realidad en el contexto propio y natural y aporta al entendimiento de la forma en que los sujetos implicados perciben el problema e interpretan el fenómeno según sus propios significados. En la investigación cualitativa existe un interés por buscar el sentido de la acción humana, lo que en este proyecto da lugar a la indagación por los imaginarios, las narrativas y las representaciones en torno al tema de la memoria, la sororidad y el tejido.

Desde la hermenéutica de Paul Ricoeur, se vincula el conocimiento histórico para la comprensión del problema y se descifran los signos presentes en las manifestaciones humanas. Esto requiere de un proceso de interpretación, cuya responsabilidad es el respeto por el pensamiento del otro, para lo cual la interpretación se dirige hacia la pluralidad de discursos de los hombres y las mujeres, lo que sitúa al ser humano en el contexto de su existir. Para Agís (2003), «la hermenéutica, vista desde la perspectiva de Ricoeur, nos acerca más a la posibilidad de comprender la vida en la medida en que acorta la distancia que media entre las creaciones (...) y el mundo del intérprete» (p. 88).

2 El recorte temporal de la investigación corresponde al periodo en el que se desarrolló el trabajo de campo durante el periodo de estudio de la maestría. 
Bajo este enfoque, obtienen prioridad los actores - las mujeres pertenecientes al Costurero Tejedoras por la Memoria de Sonsón-, para lo cual es fundamental entender sus comportamientos y los vínculos entre ellas, sus intereses personales y los colectivos, las relaciones de poder que pueden surgir en este espacio y los niveles de participación, entre otros. Lo anterior facilita la participación del investigador en la comprensión del fenómeno y del problema, a fin de resolver la pregunta orientadora y alcanzar los objetivos de la investigación. La hermenéutica, para este caso, aporta a la comprensión de los procesos de construcción de memoria dados a partir de las acciones de un grupo particular: el Costurero Tejedoras por la Memoria de Sonsón. Así mismo, faculta la interpretación de los signos presentes en los artefactos creados a partir del tejido por las integrantes del Costurero.

Para la recolección y generación de la información, en la investigación se adelantaron estrategias como: i) revisión documental de fuentes que aportaran al entendimiento de los conceptos principales, con contextos o preguntas orientadoras semejantes o que brindaran información sobre el contexto histórico, político, geográfico y cultural del lugar de estudio. ii) Análisis del material visual creado previamente por el Costurero, para complementar la información rastreada en diferentes fuentes escritas durante la revisión documental. Este material aportó a la interpretación de la realidad social del grupo estudiado, gracias al lenguaje simbólico y metafórico. iii) Observación participante, aplicada durante todo el proceso de la investigación, ya que permitía la participación activa de la investigadora en las actividades del grupo (Costurero). iv) Técnicas interactivas, gracias a las cuales, a partir de la interacción grupal (producción colectiva del tejido), se da la construcción del conocimiento y el relacionamiento con los otros desde un saber particular, que en este caso es el tejido/bordado, reconocido por todas las integrantes del Costurero. Alrededor de este saber común, se construyeron los talleres de tejido/bordado como herramienta de recuperación de información, los cuales buscaban promover la expresión creativa a través de representaciones en el textil. 


\section{Memoria y sororidad en el Costurero Tejedoras por la Memoria de Sonsón}

La sororidad permite la construcción de procesos de solidaridad y reconstrucción del tejido social, en los cuales las mujeres se asocian para generar cohesión y credibilidad frente a las verdades expuestas de los sucesos vividos, pero también para aportar a los procesos de mejoramiento y fortalecimiento de relaciones comunales, vecinales, de género, entre otros. Así lo afirma la líder de esta iniciativa: «Somos mujeres que creemos en nosotras mismas. Que lo que hacemos nos ayuda para nuestra superación personal y económica». (Diálogo con tejedora LD, 2018).

La sororidad es un concepto que manifiesta la alianza profunda entre las mujeres, en el que no hay jerarquías, sino que se basa en el principio de la igualdad humana y de la reciprocidad, lo que supone compartir los recursos, los conocimientos, las tareas y los éxitos. Este concepto, desarrollado por Marcela Lagarde y de los Ríos, se sustenta en el saber solidario de las mujeres, en una alternativa política, en tanto que busca la confluencia y sintonía de las mujeres como base del relacionamiento. Estos procesos de solidaridad son afirmados por las tejedoras como parte esencial de la pertenencia al Costurero:

Nosotras, cuando hay una necesidad de algo, la una llama, la otra funciona, la otra va a las casas, que vea que a esta le pasó tal cosa. Entonces, ahí mismo nos reunimos, dependiendo lo que pase, si se le murió alguien, recogemos para hacerle un arreglo floral, si hay un enfermo, le llevamos cositas de mercado, si lo van a remitir, miramos cómo ayudamos con plata, así sea $\$ 500$ o $\$ 1000$ pesos; lo que recojamos, lo llevamos. Y así es que nosotras ya no somos como un grupo que se reúne por reunirse, sino que ya somos una familia. Vivimos al pendiente de qué necesidad tiene la una o la otra. En otros grupos va uno y faltó alguien y ni pregunta uno por qué faltó o algo. En cambio, nosotras nos reunimos y, si el día que nos reunimos faltó alguna, al menos una de todas ya sabe por qué faltó, porque 
ya se encargó de avisarle, yo no voy por tal cosa, y vivimos muy pendientes todas de todas. (Entrevista a tejedora LD, 2018)

Lagarde (2006), al desagregar el concepto de sororidad lo define como:

Sororidad del latín soror, sororis, hermana, e-idad, relativo a, calidad de. En francés, sororité, en voz de Giselé Halimi, en italiano sororitá, en español, sororidad y soridad, en inglés, sisterhood, a la manera de Kate Millett. Enuncia los principios ético políticos de equivalencia y relación paritaria entre mujeres. (...) La sororidad es una dimensión ética, política y práctica del feminismo contemporáneo. Es una experiencia de las mujeres que conduce a la búsqueda de relaciones positivas y a la alianza existencial y política, cuerpo a cuerpo, subjetividad a subjetividad con otras mujeres, para contribuir con acciones específicas a la eliminación social de todas las formas de opresión y al apoyo mutuo para lograr el poderío genérico de todas y al empoderamiento vital de cada mujer. (pp. 3-4)

Según lo anterior, es posible inferir que la sororidad y la acción no pueden separarse. La sororidad, en tanto que involucra el vínculo y la hermandad de las mujeres, incide en la reconfiguración de los procesos políticos cotidianos como fuerza motivadora de lo público y, por ende, de generación de dinámicas sociales de acción cohesionada. Sororidad es crear vínculos, tejido social.

La sororidad y las formas de affidamento no son una invención idealista, se basan en experiencias entre mujeres que es preciso internalizar y extender hasta convertirlas en el eje de una ética política entre nosotras. Millones de mujeres no habrían sobrevivido sin el soporte, el apoyo, el reconocimiento, la transmisión de descubrimientos y la autoridad de otras mujeres. Cada vez es más urgente que utilicemos estos recursos políticos para desmontar las dificultades vitales y ampliar la cultura democrática: se trata de construir la democracia genérica entre nosotras. Ya nos hemos convocado bajo el principio del reconocimiento de la diversidad entre nosotras, ahora hace falta revindicar el principio de igualdad. (p. 6) 
Aunado a lo anterior, la autora apunta: «Qué sería de las mujeres sin el aliento y el apoyo en situaciones de crisis que son tantas. No habríamos sobrevivido a los avatares de la vida sin otras mujeres conocidas y desconocidas, próximas o distantes en el tiempo y en la tierra» (p. 1). Esto ilustra la manera en que las relaciones, las prácticas, las situaciones y las cotidianidades de las mujeres se convierten en la base de nuevas formas de solidaridad social para superar momentos de crisis y, a su vez, para proponer visiones del mundo desde una perspectiva feminista que posibilite la acción pública y la ciudadanía de las mujeres. En coherencia con esto, las tejedoras afirman,

Nos enseñamos las unas a las otras y nos apoyamos. Compartimos los algos y todo lo que llevamos. (Entrevista a tejedora A, 2018)

Si uno está haciendo una costura y uno no la entiende, entonces uno consulta a una compañera y ella le explica, le ayuda o uno va donde ella por si algo que se le olvide a uno. (Entrevista a tejedora L, 2018)

El pacto, elemento representativo de la sororidad, es el camino recorrido por las mujeres hacia la construcción de lo público femenino, pues lo público, en gran medida, ha sido establecido por las concepciones masculinas de ciudadanía y de organización del mundo. En razón a esto, Lagarde invita a reivindicar los pactos creados desde las mujeres y desde una visión feminista, que desmonte la concepción estética y política masculina aplicada a todo el conjunto de la vida, para lo cual destaca precisamente las experiencias y habilidades, el apoyo y las subjetividades generadas en la cultura femenina desde la solidaridad. En este recorrido, es posible deconstruir la agenda y los pactos de usanza masculina, las formas excluyentes de supremacía en las formas de relacionamiento social; sin embargo, más allá de esto, es importante destacar otras formas de enfrentar y superar los conflictos que se nos presentan en la sociedad, las cuales deben estar articuladas a la acción reparadora de los daños en cada mujer: 
Con estos encuentros hemos sido mujeres bendecidas, libres, sabedoras del poder que cada una tenía en su interior. (...) Tenemos todo el derecho del mundo a llorar nuestros muertos, pero tenemos el derecho y la obligación de sanarnos y ayudar a sanar a otras. Y que, como fuimos fuertes para salir de tanta barbarie como fue la guerra, ahora no somos ni la muestra de lo que fuimos. (Diálogo con tejedora LD, 2018)

En este contexto resulta apropiado hablar de los procesos de empoderamiento de las mujeres desde una visión más integradora que no separa las luchas colectivas de la vida personal, de una manera en que todo aquello que se hace desde lo individual tiene una influencia en las acciones colectivas y viceversa. Ya que, como menciona Lagarde, lo personal es realmente político, de esta forma, se deconstruyen aquellas visiones y acciones homogeneizadoras de la vida social fundamentalmente masculinas.

El empoderamiento de las mujeres desempeña un papel fundamental en su vida social y política. Asimismo, el concepto de autoestima vinculado al empoderamiento enfatiza la necesidad de correspondencia entre los cambios ocurridos en el mundo exterior (del nivel de las estructuras sociales) y los cambios subjetivos para avanzar en la incidencia de las mujeres en su propia vida. Para Lagarde (2000), «lo fundamental desde la perspectiva feminista es que fortalecer la autoestima consiste en lograr el empoderamiento personal y colectivo de las mujeres; y en potenciar nuestra capacidad democratizadora del mundo» (p. 8). De ahí que atribuya gran importancia a la autoestima como base del empoderamiento, desde la cual se trabaja por las necesidades e intereses personales y, a su vez, por el desarrollo de la libertad y emancipación de las mujeres.

Es claro que la mejoría de las condiciones sociales solo puede lograrse socialmente; esto requiere, como lo explica Lagarde, por un lado, que haya aceptación de pertenecer al mismo género y de compartir la especificidad o diferencia sexual y, por el otro, que haya la aceptación 
y el reconocimiento de otras mujeres como merecedoras de los mismos derechos y libertades. Dicha relación es condición necesaria para la sororidad.

Al quedar colocadas en el mismo compartimento, las mujeres compartimos con las otras mujeres un sendero por asignación política patriarcal. Sin embargo, la sororidad implica una decisión y una elección. Hemos decidido que para salir de ese compartimento vamos juntas y nos elegimos como legítimas equivalentes. (pp. 8-9)

De acuerdo con esto, se identifica que las iniciativas de memoria - concepto tomado del Centro Nacional de Memoria Histórica-, en algunos casos, son trabajos, prácticas, performances, procesos o acciones, que se pueden realizar de manera individual o colectiva, y que hacen uso de medios visuales, auditivos, táctiles, olfativos, etc., para expresar la vivencia del conflicto armado y socializar la experiencia en aras de la no repetición. Son la materialización de historias vividas en el marco del conflicto armado, que buscan evidenciar el dolor y la injusticia, pero a su vez son la certeza de la fuerza y el tesón para salir adelante y el interés de restaurar el tejido social roto por la violencia.

Las iniciativas de memoria son acciones, discursos o prácticas que aparecen como respuesta o resistencia al conflicto armado, y que nacen como una manera de expresar las memorias del conflicto en lenguajes diversos, "formas creativas, cotidianas, simples, de expresar esas memorias, de marcar los lugares donde se presenciaron las acciones violentas» (Arenas, 2012). Son creadas para dar a conocer relatos y experiencias invisibilizados por la violencia en el marco del conflicto armado colombiano y se dan en diferentes momentos posteriores a los hechos violentos, ya que «(...) hay, como es sabido, temporalidades de la memoria, cosas que solo pueden aflorar paulatinamente, a medida que pasan los años y la distancia atenúa la angustia, libera el secreto o la prohibición» (Arfuch, 2013, p. 25). 
Las iniciativas de memoria elaboradas por mujeres en procesos de sororidad son representaciones de la no-violencia, que necesitan de la violencia para considerarse como válidas. Una gran parte de estas surge porque las mujeres son el resultado de la guerra, pues muchas sobreviven a sus padres, esposos, hijos o sobrinos, y asumen la posibilidad de convertirse en agentes de cambio y sujetos sociales que quieren dejar rastro de los hechos violentos a través de narrativas pacíficas. Una de ellas manifiesta: "porque por el Costurero nos olvidamos de muchas cosas que nos sucedieron, sobre el pasado (entrevista a tejedora L, 2018).

Romero (2008) afirma que, «cuando se trata de guerras, la palabra víctima evoca un conjunto de imágenes altamente marcadas por el género» (p. 298). El hecho de que las mujeres sean las principales víctimas del conflicto armado dio lugar a su empoderamiento a través de una destreza que, en el caso del Costurero, es el tejido, lo que es evidente cuando una de ellas dice: «el Costurero hoy me ha ayudado a seguir adelante» (entrevista a tejedora R, 2018).

La relación entre las iniciativas de memoria y las resistencias no-violentas, como lo enuncia Ricoeur (2012), cumple con las siguientes condiciones:

La primera condición a la que debe satisfacer una doctrina auténtica de la noviolencia es el haber atravesado, en todo su espesor, el mundo de la violencia. (...) Es preciso practicar hasta lo último esta toma de conciencia de la violencia, ir hasta donde ella exhibe su trágica grandeza y aparece como el resorte mismo de la historia, cual «crisis» —el «momento crítico» y el «juicio»— que, de repente cambia la configuración de la historia. (...) Esto es, si la conciencia cuenta con qué reivindicarse contra la historia y reconocerse perteneciente a un «orden» distinto de aquel de la violencia que hace la historia. (p. 46)

Las acciones para recordar son diversas, múltiples y dinámicas; la memoria no es el pasado en sí mismo, sino una huella, un rastro, una impronta de la memoria que lo representa. Para entender la memoria 
que se reconstruye desde el tejido como iniciativa de memoria, se debe analizar el contenido y la forma, ya que la manera de narrar un hecho habla, más que del hecho, de un momento histórico, político y cultural; de una postura religiosa, un nivel educativo, un momento específico del clima; de la geografía; de un espacio y un tiempo determinados.

Existen muchas iniciativas para librarnos del mal y una de ellas es la memoria. Por eso, las iniciativas de memoria tienen gran pertinencia social y política, pues se constituyen como herramientas de difusión de la información. El Costurero Tejedoras por la Memoria de Sonsón construye su identidad narrativamente, a partir de los tapices creados por ellas a través del tejido; de esta manera documentan hechos conflictivos como si fuera una fotografía de ese momento histórico. Al dialogar con las tejedoras sobre sus sentimientos frente al proceso de creación del telón de las mariposas (uno de los resultados de los talleres de tejido y bordado) manifestaron,

El telón de las mariposas nos inspiró como a lo que éramos antes, que en ese momento no lo reconocíamos o no lo sentíamos. Antes nos sentíamos como unos gusanos, que no sabíamos nada, nos sentíamos muy poca cosa ante las otras personas. Y con ese trabajo que hicimos empezamos a descubrir un montón de cosas, de fortalezas, de conocimientos, de emociones. Porque usted nos trajo un material y nos dijo, «a hacer las mariposas». Era un trabajo libre, que cada una lo hiciera como quisiera; entonces, al hacer eso, al cada uno escoger como hacerlo, de qué colores, nos dimos cuenta de lo que éramos capaces, de las diferentes expresiones y conocimientos que teníamos escondidos. Y el mayor logro fue que reconocimos nosotras mismas los avances que tenemos del antes y el ahora. Ya que somos iguales a todas las otras personas, que no esperamos a que el otro haga para copiar. (Diálogo con tejedora LD, 2018)

El Costurero está conformado únicamente por mujeres. En la actualidad son 17, víctimas sobrevivientes de hechos atroces como asesinatos de familiares y amigos, secuestros de familiares, desplazamientos forzosos, amenazas, pérdida de bienes, tortura y hostigamientos, además 
de lesiones personales de orden físico y psicológico. Estas mujeres se reunían para elaborar un duelo conjuntamente y sin miedo, en un momento en el que no se podía hablar públicamente de los hechos victimizantes, ni de las víctimas, y mucho menos de los victimarios. Respecto al temor posterior a los hechos victimizantes, afirman:

Me mataron a un hijo y me desaparecieron el otro, que no me lo han reconocido. Me aporrearon a mi esposo por allá en la vereda y por eso nos tuvimos que venir (...). Después que lo aporrearon, él se vino porque él siguió con mucho miedo que no lo fueran a ver por allá, entonces, cada vez que veía asomar un grupo armado, él decía ya van a venir otra vez por mí (...), yo le dije que ya yo no aguantaba allá sola, (...) me daba mucho miedo quedarme durmiendo ahí en la casa, nos teníamos que ir a otra casa más arriba donde vivía otro hijo, porque me daba miedo, porque eso cuando uno menos pensaba tocaban la puerta en la noche. (...) Yo veo esos montes y me parece que por allá salen esos grupos armados, como salían, un monte verde y salía un montón de gente verde; eso me marcó, mejor dicho, me marcó. Ahora, acordarme de cuando pasaban esos helicópteros, que pasaban encima de la casa era echando plomo, uno no sabía ni dónde meterse. (Entrevista a tejedora Rb, 2018)

A mí, pues, ni me gusta recordar, porque eso es muy duro, (...) uno no podía hablar para nada. Me mantenía muy preocupada con mi esposo. (...) Eso es una cosa muy dura. No me gusta ni volver a recordar esto, mamita, ya. (Entrevista a tejedora BB, 2018)

El objetivo de estos encuentros es, entre otras cosas, el fortalecimiento de la Asociación de Víctimas por la Paz y la Esperanza y la tramitación del dolor a partir de ejercicios en torno al tejido, que trabajen los temas de memoria, reconciliación y reparación a víctimas. Las tejedoras fundadoras del Costurero insisten en que no sería posible hacer lo que hacen hoy en día sin haberse expuesto como vulnerables ante los demás, para compararse e interpretarse en el marco de la guerra. Hay historias desgarradoras, que en su momento ellas consideraron de naturaleza más trágica que la propia; esto les permitió reflexionar y salir 
adelante: «si yo he sufrido tanto y mi historia no se puede comparar con la de alguna de mis compañeras, y ellas han logrado salir adelante, yo también soy capaz, yo también puedo» (diálogo con tejedora, 2017).

Lo anterior confirma lo anotado por Arfuch (2013): «sin embargo, y en tanto uno nunca recuerda solo, (...) sino en el contexto de su medio social, esa transmisión es la clave y el don que guía el devenir de las generaciones, el principio de reconocimiento y pertenencia (...)» (p. 68). La líder del Costurero afirma: «el Costurero Tejedoras por la Memoria de Sonsón es una propuesta para el alma, es un trabajo reflexivo, simbólico. Un espacio para el encuentro y la memoria. Cada que nos reunimos, siempre es evocando eso, para trabajar sobre la memoria».

Las mujeres pertenecientes al Costurero Tejedoras por la Memoria de Sonsón se unieron a tejer memoria para sanar heridas y mejorar la convivencia; así, dejan el rastro de esa memoria en objetos tangibles que permiten que esta información y estos hechos circulen intergeneracionalmente. En el Costurero, hacer memoria a través del tejido, fortalece los vínculos de unión y de sociabilidad; al confiar en las puntadas se impregnan los saberes propios como si se elaborara un proceso de duelo con cada movimiento de la aguja, así, una parte de la memoria personal queda en el textil. La interacción que se genera a través del Costurero permite la construcción de significados compartidos que interpretan el pasado individual y producen acuerdos comunes de identidad y memorias colectivas.

Algunos de los productos construidos desde el Costurero Tejedoras por la memoria de Sonsón, que «narran los procesos de resistencia, reconciliación, reparación y algunos de los hechos violentos ocurridos en la zona en el marco del conflicto armado» (Centro Nacional de Memoria Histórica, 2017), son:

\section{0}

Creación de muñecos y muñecas. Esta dinámica buscaba que las tejedoras lograran representar su duelo en un personaje tejido (figura 1), 
el cual debía tener nombre, identidad e historia de vida. Algunas de las tejedoras eligieron un ser ausente conocido, lo que les permitió recordar -en un proceso de conmemoración-y elaborar el proceso de duelo. Dado que este fue uno de los primeros ejercicios de trabajo conjunto, algunas tejedoras manifestaron dificultades para lograrlo, por lo que debieron crear un nuevo personaje que representara el hecho que en ese momento no eran capaces de nombrar desde la experiencia personal. Otras cuentan que era más fácil para ellas dotar a estos muñecos con una nueva identidad, en la que estaba incluido solo aquello que se atrevían a contar, pues la confianza apenas se estaba creando entre ellas. La dificultad estaba en ser capaces de materializar a ese ser querido que les fue arrebatado y compartir su tristeza como una forma de dejar un testimonio que rememore los hechos y evite su repetición.

\section{Figura 1. Muñecas y muñecos de trapo elaborados por} algunas de las integrantes del Costurero Tejedoras por la Memoria de Sonsón. Técnica: costura y bordado. Medidas: 40x25 cm. Año de elaboración: 2010 .

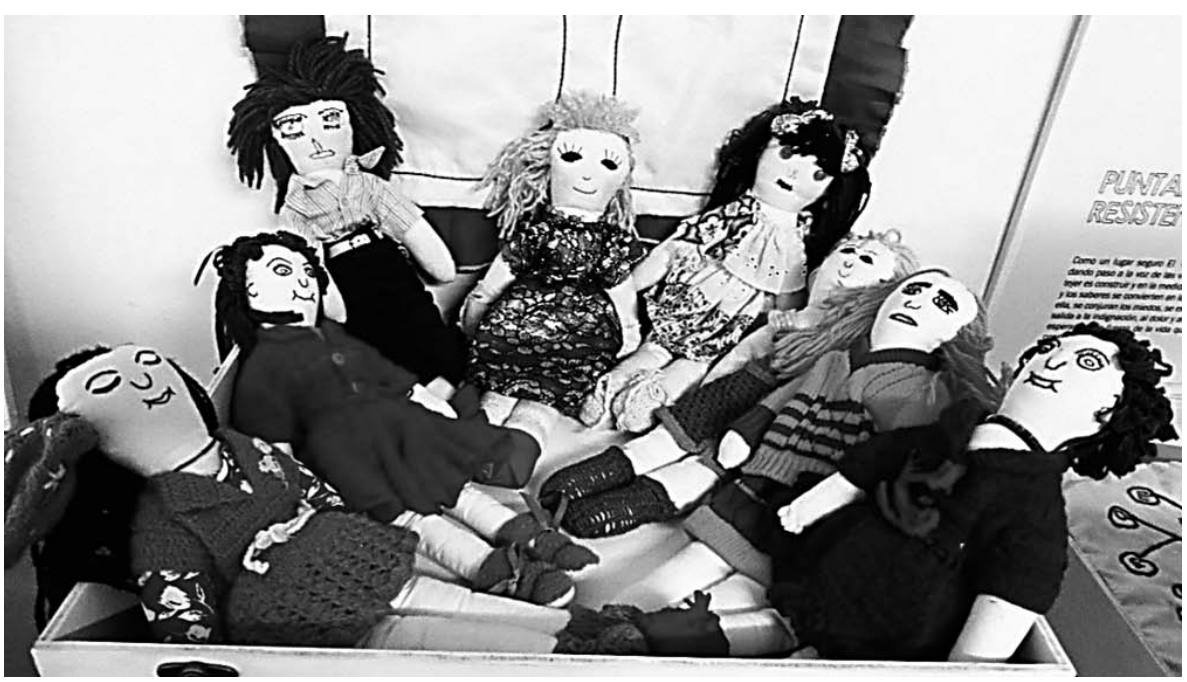

Fuente: fotografía tomada por Ana María Sossa Londoño. 


\section{1}

Elaboración de quitapesares. Estos son unos muñecos que varían en tamaño, materiales y color (figura 2), según su creadora, pero que cargan simbólicamente con el poder de llevarse las tristezas de quien lo tenga en sus manos. Se les atribuye a estos quitapesares la capacidad de eliminar los miedos y las preocupaciones de quien los tenga. Es uno de los elementos más representativos del Costurero y, a la fecha, siguen creándolos.

Figura 2. Quitapesares elaborados por el Costurero Tejedoras por la Memoria de Sonsón. Técnica: mixta. Medidas: $3 \mathrm{~cm}$ de alto. Año de elaboración: 2011 .

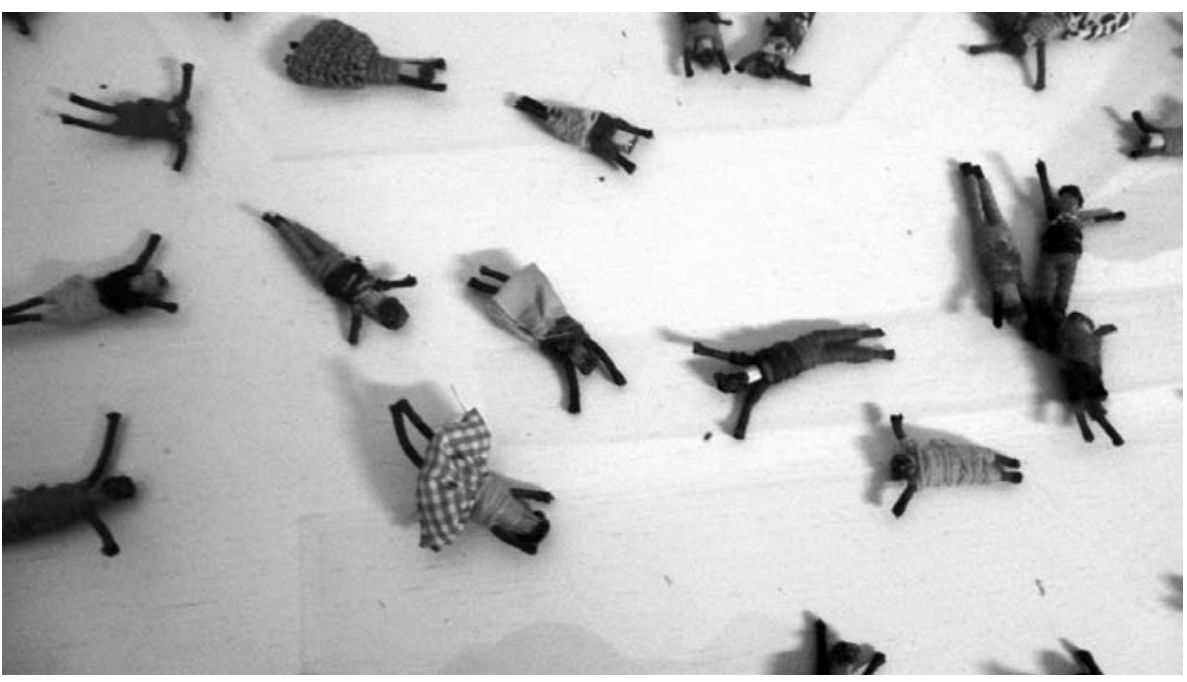

Fuente: fotografía tomada por Ana María Sossa Londoño.

En este mismo año elaboraron unos cojines bordados que representaban el árbol de la vida (figura 3). En los cojines bordaron un árbol genealógico de cada víctima/sobreviviente-tejedora, el cual representa a su familia, incluidos los miembros ausentes y los sobrevivientes. Esta actividad buscaba generar reflexión en torno a la familia: cómo era antes del conflicto y cómo se constituye después de él. 
Figura 3. Los árboles de la vida. Cojín bordado por el Costurero Tejedoras por la Memoria de Sonsón, que representa el árbol de la vida de una de sus integrantes. Técnica: bordado. Medidas: $50 \times 50 \mathrm{~cm}$. Año de elaboración: 2011 .

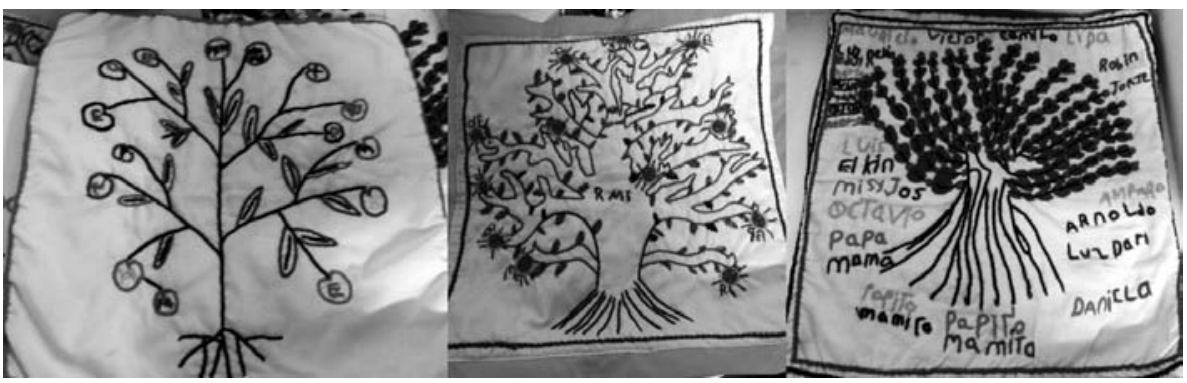

Fuente: fotografía tomada por Ana María Sossa Londoño.

El 9 de abril del año 2014, día nacional de la memoria y solidaridad con las víctimas del conflicto armado, la municipalidad les entregó el Salón de la Memoria, un espacio ubicado en la Casa de la Cultura de Sonsón, donde tienen la posibilidad de encontrarse y celebrar exposiciones permanentes e itinerantes de su trabajo (figura 4). De esta manera, han logrado que la memoria y el espacio fortalezcan un vínculo de gran importancia, ya que este último "constituye un dispositivo y soporte fundamental en la articulación, reproducción y transformación de la memoria» (Kuri, 2017, p. 19). Así, este se ha convertido en un lugar de memoria, que «deviene en tal solo en la medida en que es utilizado para recordar. (...) centrándonos en los usos y apropiaciones que, por medio de acciones de memoria, enuncian, articulan y construyen sentidos del pasado» (Piper et al., 2013, p. 26). 
Figura 4. Salón de la Memoria de Sonsón ubicado en la Casa de la Cultura de Sonsón. Tapices bordados por las tejedoras del Costurero.

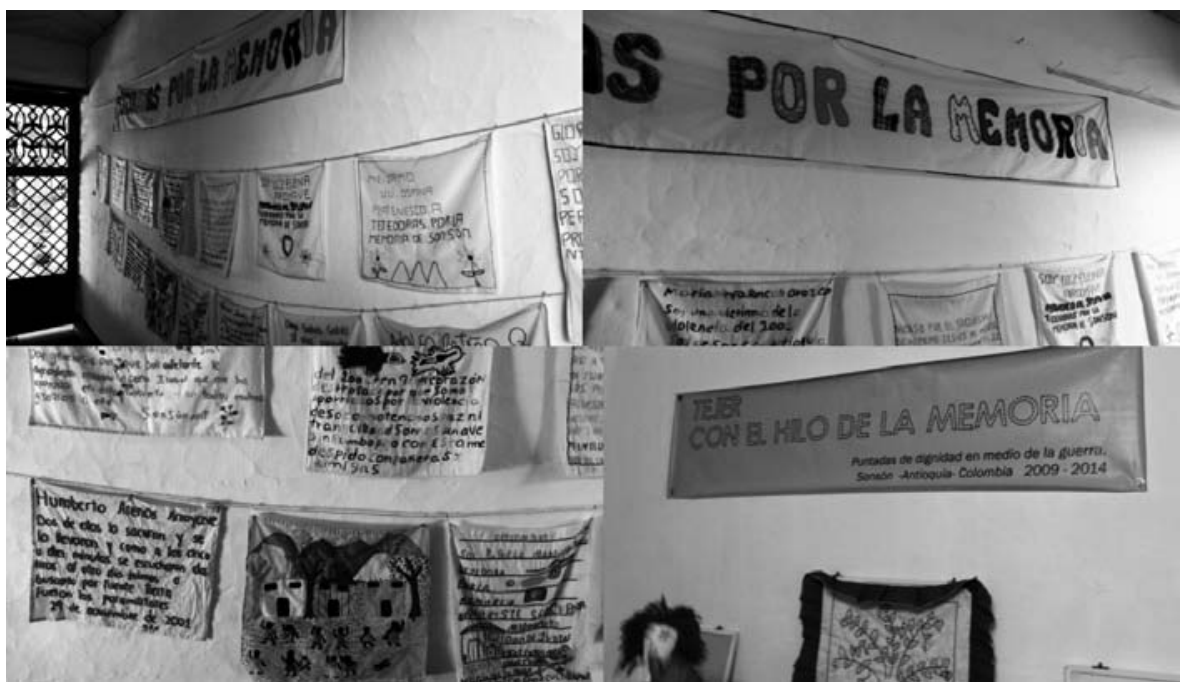

Fuente: fotografía tomada por Ana María Sossa Londoño.

Este mismo año, ellas fueron galardonadas por la Gobernación de Antioquia con el reconocimiento "Antioqueñas de Oro» en la categoría colectiva, como un reconocimiento a sus aportes al municipio y a los procesos de construcción de memoria del departamento y del país. Más adelante, en el 2016 se estableció la Red de Tejedoras por la Memoria y por la Vida, a la cual se vincula el Costurero, con el fin de construir memoria histórica y usar el tejido como narrativa mediante el trabajo colaborativo. Hoy en día, se reúnen cada semana, los lunes en la tarde en el Salón de la Memoria.

En suma, se entiende la sororidad como el camino que las mujeres recorren colectivamente para aportar desde los propios sentidos, vivencias y cotidianidades, acciones de reivindicación frente al mundo, que en últimas significa construir espacios de empoderamiento social. 
Este concepto relacionado con la idea del empoderamiento de las mujeres ha sido de vital importancia para el análisis de la experiencia del Costurero Tejedoras por la Memoria de Sonsón. Las tejedoras han adquirido dominio y control sobre su vida, han fortalecido su convicción, creencia y confianza en sí mismas y han desarrollado un ejercicio de autonomía, en el que es evidente que la sororidad y el empoderamiento, aun cuando son derechos, conllevan asimismo una gran responsabilidad.

\section{El tejido en los procesos de construcción de memoria adelantados por mujeres}

Porque con el tejido encontramos la tranquilidad y la sanación. Oportunidad de distraernos y no pensar en lo negativo.

Entrevista a tejedora A, 2018.

El tejido es un saber ancestral, que permite comunicar temas en un lenguaje universal; es un medio de expresión vital para la mujer y un medio de escritura femenina, que, al ser creada con las manos, adopta simbólicamente el sello personal de la visión del mundo; es decir, lleva la firma y huella de quien teje. El tejido se relaciona principalmente con una actividad femenina, artesanal y doméstica; saber tejer es una destreza que se aprende a través de largas tradiciones y que se transmite de generación en generación.

Tradicionalmente, a la mujer se le han destinado las artes menores o artesanías - los textiles, el bordado, la costura, la alfarería, la cocina-, y a los hombres lo que se conoce socialmente como las artes mayores -la pintura, escultura, arquitectura, música-: es decir, concomitantemente, una distribución sexuada de materiales, técnicas, destrezas, lugares de adquisición de saberes, conjuntamente con la separación de los espacios públicos y privados. (González, 2002, p. 97) 
A pesar de que el tejido es considerado como un oficio fundamentalmente femenino relacionado a la vida cotidiana del hogar, la realidad es que esta técnica trasciende lo doméstico, en la medida en que comprende aspectos como la observación, la reflexión, el tacto, la resignificación y las subjetividades. «Tejer implica abrir desde el centro» (López 1994, p. 97), despertar la creatividad, conectarse con el interior, liberar preocupaciones; es un puente para recuperar la propia voz. Toda persona que ejerza el oficio del tejido o la técnica textil requiere de confianza en sí misma y autoestima, la cual se fortalece a través de la sororidad, ya que siempre hay incertidumbre acerca del resultado final del artefacto que se está creando. En ese sentido, «el misterio que forja el devenir» (López, 1994, p. 97) hace parte implícita de estos procesos, pues, entre puntada y puntada, el tejido va adoptando sentido, y con el paso del tiempo este se hace legible y significativo.

En consecuencia, se entiende el proceso del tejido en su doble capacidad de ser literal y metafórico, ya que, en un primer momento, se desarrolla el movimiento rítmico y alternativo que se forja con la aguja y el hilo a través del textil, y en un segundo momento, el paso del tiempo, que es el movimiento por el que pasa el cuerpo y el alma. El fruto de estos dos momentos es la creación de un textil testimonial que requiere el ejercicio de la memoria para revivir aquellos hechos violentos que se quiere denunciar. Luego, en medio de lazadas, la aguja con hilo que atraviesa la tela se enreda y crea un nudo, que representa aquellos obstáculos en el camino, las dificultades emocionales para acceder al recuerdo, el miedo de narrar los hechos sucedidos por temor a que alguien los escuche, los conflictos internos que surgen al compartir ese momento íntimo con otras personas, conocidas y desconocidas, etc. Después, este nudo, con tiempo y paciencia, se va soltando, lo que da lugar a la confianza de compartir las experiencias vividas y apoyarse en las compañeras del Costurero como parte de un grupo de apoyo, lo que finalmente establece la posibilidad de seguir tejiendo. El artefacto tejido es la fotografía de todo un camino de sanación, comprensión y tramitación del dolor; asumir el tejido como un acto reflexivo les permite a las tejedoras interpretar esa fotografía. 
Esta afirmación se soporta en lo relatado por ellas:

Que puntada tras puntada contamos del destierro, del dolor, del sufrimiento, pero también de la esperanza, de la fe, de la resistencia; y todo esto es vital para no olvidar. Cada costura es también un vínculo de memoria, que transmite en el presente las vivencias, los sentimientos, las ausencias del pasado, se les da la dignidad a los sobrevivientes y se hace justicia con aquellos que no están. Y cada una de nosotras hemos aprendido a compartir el dolor y a ser un apoyo para otros, para otras personas. A saber, que la palabra sana, pero el silencio necesita de un tiempo. En los tejidos narramos una vida que batalla contra la impunidad; no solo narramos el dolor, el sufrimiento, sino las luchas por la justicia y la no repetición. (Diálogo con tejedora LD, 2018)

En sintonía con lo anterior, López Castaño (1994) afirma que,

el tejido está además asociado al hecho tranquilizador que el hilo dispone, ese lazo que encontramos en medio del abismo y que ata o retiene la caída es, diríase, un símbolo de continuidad, un dispositivo de salida del laberinto (...), es un ritmo productivo que se opone al desgarramiento como a la ruptura y que repara o reúne dos partes separadas. El mundo diurno y nocturno se reencuentran en el tejido como apartes de un hito convenido donde la continuidad está implicada, solo hay una aparente separación entre la vida y la muerte, entre la noche y el día, entre el mundo de la conciencia y el orden ignorado de los sueños, (...) todas estas recurrencias simbólicas incontestables subtienden el nudo de los lazos que emulan el destino. (p. 98)

El tejido como materialidad es escritura, en la que se cuenta lo que al habla no le es permitido decir. El tejido es vía de expresión, a través de este se comunican y graban ideas sobre la tela, tal como estas se escribirían sobre el papel. Mediante el tejido se pueden contar historias, hacer referencia a hechos importantes, producir relatos, develar la posición personal o grupal frente a un suceso o una decisión, hacer denuncias, 
etc. Es un modo de expresión y comunicación personal y grupal, una herramienta mediadora y un acto reivindicativo entre la memoria y aquellos que contemplarán la obra resultante. La técnica textil tiene la posibilidad de ser herramienta de reclamación o denuncia desde un uso transgresor y subversivo.

Para el Costurero Tejedoras por la Memoria de Sonsón, el tejido es la práctica seleccionada para explorar y compartir las memorias, con un sentido reflexivo y comunicativo, en el que se materializan las narrativas de las mujeres integrantes. Las narrativas que se tejen en este espacio visibilizan hechos victimizantes, injusticias e historias de violencia. Para Arias (2017), «estos conocimientos y reflexiones se expresan a través de narrativas textiles que constituyen materialidades con una fuerte carga social y cultural, producto de la utilización de telas, agujas e hilos» (pp. 53 y 54). El tejido como una narrativa recupera y construye la memoria y deja legado de la experiencia vivida; es una construcción colectiva que parte de un proceso individual: «narrar es deambular por las huellas de la memoria que borran nuestra identidad y la rehacen. Es, diríase, la forma como accedemos a otro modo de comprendernos y de sentirnos como consecuencia de un asomarnos a la ventana del tiempo» (López, 1994, p. 100).

Los tejidos creados desde el Costurero Tejedoras por la Memoria de Sonsón se constituyen como un insumo de información y verdad, que contribuyen a la historia del conflicto en el municipio de Sonsón, en la subregión del Oriente antioqueño, en el departamento y en el país. Los tejidos creados en este espacio tienen un valor y particularidad propios, en tanto que transitan entre un arte pasivo y contemplativo y una resistencia no violenta o una protesta frente a un suceso, ya que exponen públicamente escenas, puestas sobre una tela, que narran hechos determinantes en la dinámica del territorio.

Aun cuando el resultado final del artefacto tejido es importante, ya que funciona como evidencia o denuncia de algún hecho, el proceso es 
realmente el más importante. El tiempo que se dedica a coser, tejer o bordar, es tiempo de conversación, de diálogo, de reflexión, de maduración del proceso propio de cada víctima; a través del acto de tejer se llega a un estado de conciencia, silencio, escucha y tranquilidad gracias a la concentración. Se busca que los materiales sean de uso común, para que el préstamo y el compartir de estos implementos facilite la conversación. Las telas, las agujas y el hilo son los vehículos activos de la comunicación y la transmisión de la memoria y el tejido es, entonces, una herramienta que permite el recuerdo y la reflexión previa a la intervención del textil; el único riesgo que asumen las tejedoras es que, en cada puntada, podrían llegar a contar una verdad. Esta técnica brinda la posibilidad de tener un espacio propio de intimidad y autorrealización, como lo evidencian las tejedoras: «mientras estoy cosiendo (...) se me van perdiendo los pensamientos malos», "yo me pongo a coser y ahí voy botando mis penas» o «ahí disipa uno muchas cosas».

En este sentido, Arias (2017) asegura que,

coser, tejer, bordar pueden ser actos de expresión individual, que denotan preocupación y cuidado por quienes se aman, destinados a cubrir, adornar y proteger; pero igualmente actos colectivos insertos en dinámicas sociales y expresión de movimientos de distinta naturaleza. De esta manera, se convierten en actos creativos atravesados por procesos de comunicación colectiva, con un simbolismo desarrollado desde las márgenes, desde orillas que interpelan formas estéticas legitimadas, conjugando tradiciones rurales y locales, con saberes y técnicas de diferente procedencia. Las materialidades que se producen puestas en la escena pública, no solo inspiran a otros que pueden contemplar «bonitos ejercicios coloridos», sino que además pueden llegar a constituir actos compartidos de solidaridad y de memoria. (p. 62)

De manera complementaria, cuando se les preguntó a las tejedoras si el tejido era una técnica que les permitía unirse como grupo, ellas expresaron: 
El tejido nos ayuda a estar unidas, porque mire que todos los lunes corremos todas es a coser y a charlar, y tomamos el algo. Sí, la costura sí nos une. (Entrevista a tejedora AD, 2018)

Sí, señora, muy unidas, muy bueno. Porque estamos reunidas y así no sentimos aburrición ni nada, sino así nos entretenemos todas muy bueno. (Entrevista a tejedora BS, 2018)

El tejido y los artefactos resultantes de esta técnica tienen diferentes funciones. La primera es que equivalen a un ejercicio terapéutico que les otorga voz a los recuerdos, libera las experiencias y externaliza las emociones, los dolores y las tristezas. El tejido como forma de terapia se utiliza en diversas disciplinas, pero especialmente en el área de la salud; a través de este se pretende la transición de un estado de duelo y luto a uno de comprensión del nuevo proyecto de vida, gracias a la confianza y la autoestima adquiridas. En segundo lugar, el tejido como un acto político trabaja con el trauma, construye la memoria, transmite conocimiento y es testimonio y reclamo ante la violación de los derechos humanos. En el tejido nos reconocemos como sujetos de derechos, en una interlocución no violenta, que intervienen en la búsqueda de la paz. En tercer lugar, el tejido como una forma de participación social, en la que las mujeres se movilizan en torno a un mismo fin, lo cual permite ejercicios de sororidad como en el caso del Costurero Tejedoras por la Memoria de Sonsón, en donde la formación de un colectivo les da respaldo para asumir posturas políticas y participar de las luchas que les conciernen. Finalmente, el tejido también funciona como una manera de crear economías colaborativas y obtener recursos económicos que les permitan subsistir y satisfacer las necesidades básicas que cada una de las participantes tiene.

La ventaja de esta técnica radica en que el tejido perdura en el tiempo como materialidad, lo que hace que estos textiles testimoniales lleguen a nuevas generaciones o a otros lugares del mundo y den evidencia de los hechos ocurridos, en la búsqueda de la no repetición, la justicia y la 
paz. Como lo afirma una de las tejedoras, «en el tejido se plasma lo que pasó» y el resultado de este tejido queda como el rastro de ese hecho inolvidable.

Finalmente, para entender el tejido desde lo simbólico, se deben entender las transformaciones que sufre el ser humano en su práctica. El movimiento repetitivo que se da en el tejido focaliza la atención del tejedor en el cumplimiento de su objetivo, para lo cual requiere su total dedicación; aporta la sensación de bienestar al permitirle al actor escucharse en un vaivén mental, en el que los pensamientos van y vienen al ritmo de las manos que entrelazan el hilo en la tela; fortalece los lazos sociales, al ser una actividad que favorece los encuentros grupales; se presta para dialogar sobre aquello que les inquieta, contar historias de vida e intercambiar conocimientos; y ofrece satisfacción personal por el proceso de creación propio. Tan importante como el diálogo y la conversación es el silencio. Las tejedoras manifestaban haber necesitado momentos de silencio y soledad para tramitar su dolor antes de compartirlo con las demás; el acto de tejer aportaba claridad a sus pensamientos y orden a sus ideas para reunir las fuerzas para el relato.

\section{Conclusiones}

A veces los héroes y las víctimas, son dos papeles representados por la misma persona. Todorov, 2009, p. 12.

El país atraviesa por un momento histórico en el que aumenta la importancia de trabajar sobre la memoria. Dado que las dimensiones del conflicto armado colombiano, las víctimas y los escenarios devastados por la guerra son extensos, las posibilidades de trabajar desde diferentes disciplinas y con diferentes enfoques son amplías, pues es fundamental generar investigaciones que abarquen la inmensidad del conflicto y sus consecuencias. Esta es una puerta que debe dejarse abierta para que 
otras disciplinas puedan hacer su exploración, de manera que otros profesionales puedan aportar al entendimiento de estos problemas sociales bajo diferentes miradas - como en el caso del diseño de vestuario- y priorizar acciones responsables para el bienestar del grupo social en un ejercicio de trabajo horizontal.

El tejido y el arte textil, principalmente doméstico, salen a la calle, para visibilizarse como acciones performativas de construcción del conocimiento y la memoria colectiva. La técnica textil tiene la potencia de poder expresarse, en una primera instancia, en el ámbito local, y poder escalar al ámbito nacional o internacional. Sus características físicas, como el uso de los colores, los materiales y las representaciones gráficas, hacen parte de un lenguaje universal que le permite traspasar las fronteras y ser leído y comprendido por cualquier persona, en cualquier dimensión espacio-temporal. En razón a esto, se puede decir que el discurso de los tejidos es concreto y no es especulativo.

Se debe resaltar que los procesos de formación de colectivos y de asociatividades se dan, en algunos casos, por la ausencia del Estado y la presencia de actores armados, legales e ilegales, que instauran unas dinámicas propias del conflicto. Por esto, se hace necesario reivindicar a las comunidades vulneradas, afectadas en sus derechos humanos por la violencia sistemática del país, y brindar las garantías de no repetición. La memoria es necesaria para narrar otras formas de convivencia y de pensar el conflicto; la construcción de memoria requiere seguir el proceso de la acción, la recordación y el no olvido para la justicia. Este proceso tiene como resultado la construcción de sujetos resilientes, mujeres que tejen memoria para una nueva convivencia.

Las mujeres sororas del Costurero tejen y se tejen; ellas entienden el tejer desde lo literal y desde lo metafórico, tejen piezas textiles a través del proceso repetitivo de insertar la aguja enhebrada en la tela siguiendo un patrón, y se tejen entre ellas, formando nuevas relaciones y redes de apoyo para relacionarse con el mundo. Entienden que 
el tejido es una herramienta mediadora, reparadora, sanadora, reclamadora, denunciante, recuperadora. Media conflictos, repara rupturas, sana las heridas, reclama ante las injusticias, denuncia las atrocidades de la guerra y recupera la historia para exponerla públicamente y evitar que se repita.

El Costurero Tejedoras por la Memoria de Sonsón se constituye a sí mismo y a las mujeres integrantes como una red de apoyo informal, donde se descargan las tragedias. Por este motivo, la pertenencia al Costurero representa la oportunidad de disipar las tristezas, pero a la vez de establecer vínculos de amistad que se fortalecen en el proceso de sanación. Este grupo trabaja en red, porque ellas tienen aspectos en común que las hacen unirse para tejerse entre sí mismas. Para que este trabajo en red sea significativo, requiere sinergia, confianza y compromiso; el hecho de tener un horizonte común, facilita la cohesión de ideas e iniciativas a desarrollar. Como bien se sabe, el todo es más que la suma de las partes, por eso, cada una de las integrantes tiene un papel esencial en la dinámica de este espacio; cada una con sus cualidades y aptitudes aporta al todo. Se recalca la sororidad del Costurero y se hace énfasis en que el poder colectivo de este grupo tiene mayor potencia que el accionar de sujetos individuales.

El proceso colectivo permite escuchar las otras experiencias para tener el valor de compartir la experiencia propia; además, al recordar en colectivo se construye la historia desde todas las aristas posibles y se alimenta de los recuerdos personales de cada una. Esta construcción colectiva de la memoria se debe hacer en un espacio seguro y posterior al fortalecimiento de los vínculos entre los integrantes, en un clima de confianza y seguridad. Para Lagarde (2000), esta es «la acción reparadora de unas mujeres con otras, cuando legitiman, apoyan y tratan de manera solidaria, terapéutica y ciudadana, a otras mujeres» (p. 6).

La práctica colectiva del tejido es primordial, ya que en ese espacio se socializan aspectos de la vida cotidiana, noticias de interés del 
municipio y oportunidades para nuevos proyectos, entre otros. Esto fortalece los vínculos de vecindad, pero más estrechamente aquellos de sororidad, gracias a los cuales, ante las necesidades de los otros se empatiza y se genera una red de apoyo para salir adelante. El significado que tiene el Costurero y la participación activa para la vida de las tejedoras va más allá, en este momento, del proceso de mitigación del dolor por el hecho violento o de la construcción de la memoria en torno a ese suceso; se consolida como un espacio para el aprendizaje, la socialización y la amistad. De manera complementaria, el tejido también permite compartir los saberes individuales para el bienestar del grupo, cuando se aprende o se enseña un saber específico que favorece las posibilidades de crecimiento del Costurero desde un horizonte, unos objetivos y unas estrategias comunes. Estas afirmaciones son evidentes en los relatos de las tejedoras:

Unas saben unas cosas, y otras, otras cosas y nos ayudamos mutuamente. (Entrevista a tejedora R, 2018)

Algo muy bueno, muy importante, porque al comienzo uno iba como por cumplir, como por el sacrificio que hacían de venir desde Medellín a estar con nosotras, o sea en ese momento no veíamos sino eso, el sacrificio que ella hacía, y ya vimos que, al tejer, empezando esas clases era muy duro las preguntas que ellas traían, porque era como recordar, trabajamos la memoria, la reconciliación, era como recordar lo que nos había pasado. Pero ya, al paso que íbamos trabajando, íbamos viendo de que eso nos ayudaba para... el tejer nos estaba ayudando para irnos sanando. En el momento no lo veíamos, lo estamos viendo apenas ahora. (Diálogo con tejedora LD, 2018)

A partir de estar en esos encuentros (...) y por medio del Costurero me siento muy animada y contenta. (Diálogo con Tejedora F, 2018)

A través de los encuentros las tejedoras evidencian su poder creativo y su capacidad de transformar la historia, de agenciar transformaciones en las esferas micropolíticas y afirmarse como individuos reconocidos 
por lo que pueden lograr (Arias, 2017, p. 68), como se deduce de los relatos expuestos:

Porque, cómo te dijera yo, consigue uno más amistades, aprende más, uno se entretiene, uno, si está en la casa, todo el día le resulta quehacer, pero entonces uno está esperando que ya llega el lunes, que ya llega el lunes para irse para el Costurero, entonces allá nos entretenemos, conseguimos nuevas amigas. Si la una aprendió una nueva técnica para trabajarla, sea bordado en tela, sea en crochet, sea lo que sea, entonces ahí la una le colabora a la otra. (Entrevista a tejedora BB, 2018)

Me siento muy animada y contenta por pertenecer al Costurero, del cual aprendemos muchas cosas como el compañerismo, la tolerancia y el respeto. (Entrevista a tejedora FB, 2018)

El proceso de tejer, bordar o coser, como movimiento rítmico repetitivo, le permite al cuerpo físico conectarse con su ser interior. La experiencia por la que atraviesa cada tejedora es realmente importante, porque le hace posible recordar y entenderse en su pasado, reflexionar, tramitar el dolor y externalizar las sensaciones y emociones a través del diálogo. Se resalta en este proceso la necesidad de un equilibrio entre las conversaciones y los silencios, que faculten la interlocución de manera no violenta mediante el tejido. Este tejido da cabida a la comunicación de diversos temas en un lenguaje universal. El textil es la primera casa que habitamos, con la que nos cubren al nacer y la que nos da la seguridad de relacionarnos con el mundo. Se constituye como una forma de escribir, de anunciar y denunciar. Pero, para lograr esta expresión, se requiere de autoestima y de seguridad en sí mismo a fin de superar la incertidumbre del devenir.

El ejercicio de consolidación de la memoria se da primero con la palabra en el diálogo y luego en el tejido, desde el artefacto tejido. Para eso, primero se debe vencer el miedo y generar confianza en la comunidad con el objetivo de que puedan develar los significados de la memoria 
y dotar de sentido al sujeto que resiste y persiste. Así lo mencionan las tejedoras al afirmar que la necesidad está en recordar sin resentimientos, pero recordar para no olvidar y para que otras personas conozcan lo que les pasó.

Las experiencias del conflicto las compartimos contando las historias que nos pasó a cada una. (Entrevista a tejedora F, 2018)

Yo les conté a ellas, pues, lo que me había sucedido, y por qué me habían desplazado, y ellas lo entendieron y me ayudaron a superarlo, a ir superándolo. (Entrevista a tejedora L, 2018)

Porque fue una cosa muy dura, eso fue una cosa muy dura para nosotras (...) pero gracias a mi Dios uno se tiende a recuperar de todo, porque si no fuera así, madre, nos enloquecíamos. (Entrevista a tejedora BB, 2018)

Las participantes necesitaban tejer fortalezas comunes entre mujeres, a través de la complicidad y un ejercicio de acción común horizontal, crítico y participativo, en el que la diversidad de experiencias fuera el punto de convergencia para la transformación y el aprendizaje. «No se trata únicamente de proyectar el futuro, el pasado y el presente, sino de considerar y, eventualmente, crear las posibilidades a través de las cuales el futuro podrá desarrollarse» (Vásquez, 2001, p. 25).

\section{Bibliografía}

Agís Villaverde, Marcelino (2003). La hermenéutica de Paul Ricoeur en el marco de la filosofía contemporánea. Azafea Revista de Filosofía, (5), 75-97.

Arenas, Sandra (2012). Memorias que perviven en el silencio. Universitas $\mathrm{Hu}$ manística, 173-193.

Arfuch, Leonor (2013). Memoria y autobiografía. Exploraciones en los límites. Buenos Aires: Fondo de Cultura Económica. 
Arias López, Beatriz Elena (2017). Entre-tejidos y redes. Recursos estratégicos de cuidado de la vida y promoción de la salud mental en contextos de sufrimiento social. Prospectiva. Revista de Trabajo Social e Intervención Social (23), 51-72.

Centro Nacional de Memoria Histórica (2017). Costurero de tejedoras por la memoria de Sonsón. Recuperado de: http://www.centrodememoriahistorica. gov.co/antioquia/costurero-tejedoras-por-la-memoria-de-sonson

González Stephan, Beatriz (2002). Con hilo y aguja: el tejido de la otra memoria. Arrabal, 4, 97-111.

Grisales Hurtado, Natalia Isabel (director) (2016). Luces y sombras. Reconstrucción de memoria sobre La Pinera [Película]. Recuperado de: https://www. youtube.com/watch? $\mathrm{v}=$ aorqbZsm6xw

Jaramillo Gómez, Olga Elena (2014). Memorias de la guerra. Participación de jóvenes rurales en procesos de memoria desde una perspectiva intergeneracional en la región del Oriente Antioqueño, Colombia. En: Jóvenes en movimiento, (229-265). Buenos Aires: Clacso.

Kuri Pineda, Edith (2017). La construcción social de la memoria en el espacio: una aproximación sociológica. Revista Península, 9-30.

Lagarde y de los Ríos, Marcela (2000). Autoestima y género. Cuadernos Inacabados, 39, 1-18.

Lagarde y de los Ríos, Marcela (2006). Pacto entre mujeres-Sororidad. Obtenido de Coordinadora Española para el lobby europeo de mujeres-Celem. Recuperado de: http://e-mujeres.net/wp-content/uploads/2016/08/pacto_entre_mujeres_sororidad.pdf

López Castaño, Marta (1994). El tejido como escritura y el orden femenino. Historia Crítica, 9, 96-101.

Piper-Shafir, Isabel, Fernández-Droguett, Roberto e Íñiguez-Rueda, Lupicinio (2013). Psicología social de la memoria: espacios y políticas del recuerdo. Psykhe, 19-31.

Ricoeur, Paul (2012). El hombre no-violento y su presencia en la historia. En: Paul Ricoeur, Política, sociedad e historicidad, (45-54). Buenos Aires: Prometeo Libros. 
Romero, Mauricio (editor) (2008). Verdad, memoria y reconstrucción. Estudios de caso y análisis comparado. Colombia: Centro Internacional para la Justicia Transicional (ICTJ).

Todorov, Tzvetan (2009). La memoria, iun remedio contra el mal?, primera edición. Barcelona, España: Arcadia. Obtenido de: https://humanidades1historia.files.wordpress.com/2013/08/tzvetan-todorov-la-memoria-unremedio-contra-el-mal.pdf

Vásquez, Félix (2001). La memoria como acción social. Relaciones, significados e imaginario. Barcelona, España: Ediciones Paidós Ibérica. 